\title{
Cor vs. Core
}

\author{
Cor vs. Core
}

Alfredo Pinzón • Bogotá, D.C. (Colombia)

Algunas veces se usa erróneamente el anglicismo Core en lugar de Cor, quizás por la semejanza de los términos; sin embargo, estas dos palabras tienen significados diferentes:

Core: [noun] the center or most important part of something; the centre of a planet; the place of a nuclear reactor where fission happens; the muscles around your pelvis, hips and abdomen that you use in most body movements; the hard central part of some fruits.

Core: [adjective] most important or more basic; central; found in the main part of the body.

Cor: (Del latín cor):

1. s. m. (en desuso). Corazón.

Corazón: (cor lat. 'corazón' + -ac- lat. + -ón esp.; documentado en español desde 1100) [inglés: heart]

1. s.m. Órgano fibromuscular hueco, situado en el mediastino medio, con una orientación espacial que dirige su eje anatómico de atrás adelante, de arriba abajo, y de derecha a izquierda, lo que hace que la punta del corazón se sitúe en el hemotórax izquierdo. Su función es mantener la circulación de la sangre.

2. s. m. Órgano de naturaleza muscular que actúa como impulsor de la sangre y que en el ser humano está situado en la cavidad torácica.

3. s. m. Centro de algo. El corazón de una manzana.

En medicina se emplea el vocablo 'core' en su traducción de 'núcleo', por ejemplo en Anticore (anticuerpo contra la nucleocápside del virus de la hepatitis B o proteína core), pero este término no es admisible en la expresión core pulmonale.

Cor pulmonale: [inglés: cor pulmonale]:

[CIE-10: I279] Cardiopatía secundaria a una enfermedad pulmonar bronquial o parenquimatosa que sobrecarga el lado derecho del corazón, que soporta la circulación pulmonar.

Sinónimo: cardiopatía pulmonar, corazón pulmonar.

Observación: se escribe en cursiva, por tratarse de una expresión latina; si se utiliza este latinismo debe usarse completo, evitando la forma mixta: cor pulmonar.

Fuentes:

- Diccionario de la Real Academia Española de la Lengua, disponible en: www.rae.es

- Real Academia Nacional de Medicina. Diccionario de Términos Médicos. Editorial Médica Panamericana. 2012

- Cambridge Dictionary, disponible en: www.dictionary.cambrige.org

* Envíe sus inquietudes, sugerencias o comentarios a: contacto@actamedicacolombiana.com - alfpin@ hotmail.com Dr. Alfredo Pinzón Junca: Especialista en Medicina Interna y Psicoanálisis. Hospital Universitario de La Samaritana y Hospital Simón Bolívar. Coordinador del Consejo de Acreditación y Recertificación de la ACMI ${ }^{\circledast}$. Bogotá, D.C. (Colombia). E-mail: alfpin@hotmail.com

Recibido: 18/IX/2018 Aceptado: 20/IX/2018 